\title{
(6) OPEN ACCESS \\ Maternal depression is associated with injuries in children aged 2-4 years: the Pelotas 2004 Birth Cohort
}

\author{
Raquel Siqueira Barcelos, ${ }^{1}$ Iná da Silva dos Santos, ${ }^{1}$ Alicia Matijasevich, ${ }^{2}$ \\ Luciana Anselmi, ${ }^{1}$ Fernando Celso Barros ${ }^{3}$
}

- Additional material is published online only. To view please visit the journal online (http://dx.doi.org/10.1136/ injuryprev-2017-042641)

'Programa de Pós-graduação em Epidemiologia, Faculdade de Medicina, Universidade Federal de Pelotas, Pelotas, Brazil ${ }^{2}$ Departamento de Medicina Preventiva, Faculdade de Medicina, Universidade Federal de Sao Paulo, Sao Paulo, Brazil ${ }^{3}$ Programa de Pós-graduação em Saúde e Comportamento, Universidade Catolica de Pelotas, Pelotas, Rio Grande do Sul, Brazil

\section{Correspondence to}

Dr Raquel Siqueira Barcelos, Programa de Pós-graduação em Epidemiologia, Faculdade de Medicina, Universidade Federal de Pelotas, Pelotas 96020-220, Brazil; bio.raquelbarcelos@ gmail.com

Received 19 October 2017 Revised 9 December 2017 Accepted 15 December 2017 Published Online First 26 February 2018
Check for updates

To cite: Siqueira Barcelos $\mathrm{R}$, da Silva dos Santos I,

Matijasevich A, et al. Inj Prev 2019:25:222-227.

\begin{abstract}
Introduction Injuries during childhood, which mostly consist of falls, burns, drowning, poisonings and car crashes, are among the main causes of death among children and young adults in several countries. Objectives To investigate the association between maternal depression and the incidence of injuries during childhood.

Methods In 2004, children who were born in the municipality of Pelotas, Brazil, were enrolled in a population-based birth cohort, with evaluations at birth and at 3, 12, 24 and 48 months of age. Maternal depression during pregnancy was evaluated at the time of delivery. At 12 and 24 months post partum, the Edinburgh Postnatal Depression Scale (EPDS) was used. The injuries incidence rates at ages of 24-48 months and the crude and adjusted IRRs were calculated with 95\% $\mathrm{Cl}$ through Poisson's regression.

Results A total of 3533 children were analysed. The incidence of injuries was higher among children whose mothers presented depressive symptoms during pregnancy and at 12 and 24 months compared with those whose mothers did not present any symptoms. In the adjusted analysis, the IRR among girls whose mothers presented depressive symptoms during pregnancy and EPDS $\geq 13$ at 12 and 24 months was 1.31 (1.15-1.50); and, among boys, 1.18 (1.03-1.36). Interpretation Maternal depression is associated with higher incidence of injuries between 24 and 48 months of age, in both sexes.
\end{abstract}

\section{INTRODUCTION}

Injuries during childhood, which mostly comprise falls, burns, drowning, poisonings and car crashes, ${ }^{1}$ are a worldwide health problem, not only because of the morbidity that may arise, but also because such injuries are among the main causes of death among children and young adults in several countries. ${ }^{2}$ Childhood injuries are often interpreted as a work of chance, but most often predisposing factors play a role on its occurrence. A population-based study, conducted in the municipality of Pelotas, RS, Brazil, showed that the prevalence of falls, cuts and burns ranged from 5.2\% for burns during the first year of life, among girls, to $77.7 \%$ for falls during the second year of life, among boys. ${ }^{3}$ In this same study, maternal factors such as younger age ( $<18$ years), lower socioeconomic status and lower educational level were associated with higher incidence of injuries among children aged 0-4 years. ${ }^{3}$
Other factors, such as inadequate supervision, family stress, improper dwelling conditions and characteristics of the child's personality, such as hyperactivity, aggressiveness, impulsivity and distraction, also facilitate the occurrence of injuries. ${ }^{4}$ As maternal depression is a common condition associated with several child health outcomes, some authors have suggested an association between maternal depression and incidence of injuries among children. ${ }^{56}$

One of the first studies evaluating the relationship of mental disorders in mothers and injuries in childhood was conducted in England in 1978. That study explored the association not specifically of depression but between maternal psychiatric disorders and injuries among individuals younger than 16 years of age. Among those whose mothers presented some kind of psychiatric disorder, the injury incidence rate per year was higher than among the controls. ${ }^{7}$ Other studies carried out in 2012 in $\operatorname{Japan}^{8}$ and the $\mathrm{UK}^{9}$ and more recently in 2017 in England ${ }^{10}$ have pointed out that maternal depression was related to childhood accidents, often increasing as the duration of depressive symptoms increased in the mother.

Thus, the specific objective of the present study was to investigate the association between maternal depression and the incidence of injuries among children from 2 to 4 years who belong to the Pelotas 2004 Birth Cohort, in Southern Brazil. We tested the hypothesis that children from depressed mothers had increased incidence of injuries from 2 to 4 years of age.

\section{MATERIALS AND METHODS \\ Data collection}

In 2004, a third Pelotas birth cohort study was started. In Pelotas, $<1 \%$ of the deliveries occur outside hospitals. ${ }^{11}$ The Pelotas 2004 Birth Cohort included 4231 children who were born alive in all five maternity hospitals to mothers who lived in the urban area of the municipality. The refusal rate to participate in the study was $0.8 \%$. So far, these children have been visited at the ages of 3, 12, 24, 48 and 72 months and 11 years, with follow-up rates of $95.7 \%, 94.3 \%, 93.5 \%, 92.0 \%$, $90.2 \%$ and $86.6 \%$, respectively. At the time of birth (perinatal study) and during the follow-up visits, information on a series of socioeconomic, demographic, behavioural and biological characteristics was collected both from the mother and from her 
child. This information was obtained by trained interviewers through the application of a structured and standardised questionnaire. Further details of the study are available in other publications. ${ }^{12-14}$

\section{Measurement}

In the present study, information from the perinatal study and the follow-ups at 12, 24 and 48 months of age was used. Only children from single pregnancies were included in the analyses. The outcome (number of falls, cuts and burns that occurred between 24 and 48 months of age) was measured during the visit at 48 months. The section of the questionnaire about injuries began with the following questions: Now I am going to ask you a few questions about injuries that $\angle C H I L D>$ may have had. Next, they were asked, After he/she turned twoyears old, 'did $<$ CHILD $>$ fall and got injured?', 'did $<$ CHILD $>$ had a cut?' and 'did $<$ CHILD $>$ got burned?', with the following answer options: 'no', 'yes' or 'don't know'. When the answer was 'yes', the person was then asked, How many times?. The child was considered to have suffered an injury if the mother or caretaker reported the occurrence of at least one of any of the three types of injuries.

The exposure of interest, maternal depression, was investigated in the perinatal study and in the follow-ups at 12 and 24 months of age. Maternal depression during pregnancy was investigated at the perinatal interview by means of the following question: During pregnancy, did you have depression or suffer from nerves?, with the following answer options: 'no', 'yes, not treated' or 'yes, treated'. Because the number of mothers at the 'treated group' was low $(\mathrm{n}=117)$, the 'treated' and 'not treated' options were grouped into a single category for the present analysis. At 12 and 24 months of age, maternal depression was evaluated by means of the Edinburgh Postnatal Depression Scale (EPDS) ${ }^{15}$ For analysis purposes, the threshold cut-off $\geq 13$ was used (sensitivity and specificity $59.6 \%$ and $88.3 \%$, respectively). ${ }^{16}$ A composite variable was created from the responses obtained during the perinatal interview and from the EPDS results at 12 and 24 months of age, which was categorised into three groups: 'never depressed' (mothers who did not present depressive symptoms at any time); 'depressed 1-2 times' (mothers who reported depressive symptoms at one or two follow-ups) and 'always depressed' (mothers who presented depressive symptoms during pregnancy and at 12 and 24 months post partum).

The following variables collected in the perinatal study were used as potential confounding factors: mother's age ( $<20,21-30$ or $\geq 31$ years); Brazilian National Economic Index, divided into five quintiles and constructed from information on consumer goods and the head of the family's educational level ${ }^{17}$; mother's educational level $(0-4,5-8$ or $>8$ years); mother lives with a partner (yes, no); planned pregnancy; maternal smoking during pregnancy (smoking at least one cigarette per day, every day, during any trimester of pregnancy); alcohol consumption during pregnancy (regular consumption at least once a week, regardless of the amount); child's skin colour observed by the interviewer (white or black/brown/other); low birth weight $(<2500$ g) and prematurity (gestational age at birth $<37$ weeks). From the 24-month follow-up, the following variables were used: number of siblings (besides the index child) living in the household (none, $1-2$ and $\geq 3$ ); and type of family (nuclear-parents and children or extensive-including grandparents and/or other relatives).

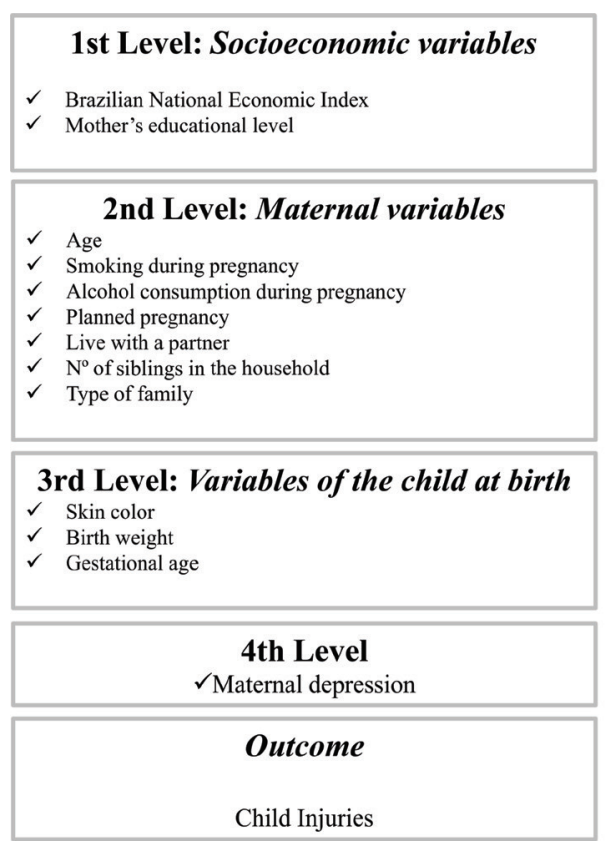

Figure 1 Model of analysis for the association between maternal depression and injuries in childhood.

\section{Analysis}

Statistical analyses were performed using the Stata software, V.12.1 (StataCorp). The outcome variable was treated as a count (number of injuries suffered by the child between 24 and 48 months of age). First, the number of injuries was calculated, along with their distribution and the proportion of the children who suffered at least one injury between 24 and 48 months of age. Incidence rate according to the exposure of interest was then calculated. Crude and adjusted IRRs and 95\% CIs were calculated by Poisson's regression with robust variance. The variables were included in the analysis by levels, according to figure 1. At each level, the $\mathrm{P}$ value of the variables was verified, and those with $\mathrm{P}$ value $<0.20$ remained in the final model to control for possible confounding effect. Based on the literature, which is consistent in indicating higher incidences of injuries among boys, all analyses were planned to be stratified according to the child's sex. ${ }^{3518}$ Complementary analyses were run to assess the relationship between maternal depression and each of the types of injuries investigated.

A total of 94 children had died in the first fouryears and 338 were lost $(n=234)$ or refused $(n=51)$ to participate at the 48-month-follow-up. Therefore, 3533 children who had full information on maternal depression and injuries were entered in the analyses. Mean child age at the 48-month follow-up was 49.55 (SD \pm 1.77 ) months, ranging from 44.71 to 61.53 months. All mothers gave their free and informed consent in writing before the interview.

\section{RESULTS}

There was interaction between the child's sex and the incidence of injuries $(\mathrm{P}=0.002)$. Table 1 shows the antenatal maternal characteristics and the characteristics of the children at birth. Almost one fifth of the mothers $(18.6 \%)$ were adolescent mothers and $15 \%$ had low level of schooling (0-4 years of formal education). Only $35.2 \%$ of the mothers reported having planned their pregnancies. Unhealthy life habits during pregnancy, such as smoking and alcohol consumption, were reported by $26.8 \%$ and $3.3 \%$ of the mothers, respectively. Except for the variable 'low birth 
Table 1 Maternal characteristics from pregnancy to 24 months post partum, children characteristics at birth and proportion of children who suffered injuries from 24 to 48 months of age: Pelotas 2004 Birth Cohort; Pelotas, RS, Brazil

\begin{tabular}{|c|c|c|c|c|c|c|}
\hline \multirow[b]{2}{*}{ Characteristics } & \multicolumn{2}{|c|}{ Boys $(n=1840)$} & \multicolumn{2}{|c|}{ Girls $(n=1693)$} & \multicolumn{2}{|c|}{ Total $(n=3533)$} \\
\hline & $\mathrm{n}$ & $\%$ & $\mathbf{n}$ & $\%$ & $\mathrm{n}$ & $\%$ \\
\hline \multicolumn{7}{|l|}{ Maternal characteristics } \\
\hline \multicolumn{7}{|l|}{ Brazilian National Economic Index $(\mathrm{n}=3533)$} \\
\hline Q1 $\leftarrow$ poorest & 355 & 19.3 & 315 & 18.6 & 670 & 19.0 \\
\hline Q2 & 333 & 18.1 & 348 & 20.6 & 681 & 19.3 \\
\hline Q3 & 364 & 19.8 & 359 & 21.2 & 723 & 20.5 \\
\hline Q4 & 400 & 21.7 & 332 & 19.6 & 732 & 20.7 \\
\hline Q5 $\leftarrow$ richest & 388 & 21.1 & 339 & 20.0 & 727 & 20.6 \\
\hline \multicolumn{7}{|l|}{ Age (years) $(n=3531)$} \\
\hline$<20$ & 339 & 18.4 & 316 & 18.7 & 655 & 18.6 \\
\hline $21-30$ & 993 & 54.0 & 893 & 52.8 & 1886 & 53.4 \\
\hline$\geq 31$ & 508 & 27.1 & 482 & 28.5 & 990 & 28.0 \\
\hline \multicolumn{7}{|l|}{ Education level (years) $(n=3499)$} \\
\hline $0-4$ & 271 & 14.8 & 252 & 15.1 & 523 & 15.0 \\
\hline $5-8$ & 743 & 40.7 & 692 & 41.4 & 1435 & 41.0 \\
\hline$>8$ & 814 & 44.5 & 727 & 43.5 & 1541 & 44.0 \\
\hline Live with a partner (yes) ( $n=3533$ ) & 1553 & 84.4 & 1434 & 84,7 & 2987 & 84.6 \\
\hline \multicolumn{7}{|l|}{ Number siblings in the household (24 months) $(n=3533)$} \\
\hline None & 878 & 47.7 & 720 & 42.5 & 1598 & 45.2 \\
\hline $1-2$ & 796 & 43.3 & 798 & 47.1 & 1594 & 45.1 \\
\hline$\geq 3$ & 166 & 9.0 & 175 & 10.3 & 341 & 9.7 \\
\hline \multicolumn{7}{|l|}{ Type of family (24 months) $(n=3533)$} \\
\hline Nuclear & 1393 & 75.7 & 1288 & 76.1 & 2681 & 75.9 \\
\hline Extensive & 447 & 24.3 & 405 & 23.9 & 852 & 24.1 \\
\hline Planned pregnancy (yes) ( $\mathrm{n}=3532)$ & 677 & 36.8 & 567 & 33.5 & 1244 & 35.2 \\
\hline Smoking during pregnancy (yes) $(n=3533)$ & 489 & 26.6 & 457 & 27.0 & 946 & 26.8 \\
\hline Alcohol consumption during pregnancy (yes) $(n=3533)$ & 63 & 3.4 & 53 & 3.1 & 116 & 3.3 \\
\hline Maternal depression during pregnancy (yes) $(n=3533)$ & 450 & 24.5 & 409 & 24.2 & 859 & 24.3 \\
\hline Edinburgh Postnatal Depression Scale at 12 months $\geq 13$ ( $n=3533)$ & 266 & 14.5 & 255 & 15.1 & 521 & 14.8 \\
\hline Edinburgh Postnatal Depression Scale at 24 months $\geq 13$ ( $n=3533$ ) & 277 & 15.1 & 280 & 16.5 & 557 & 15.8 \\
\hline \multicolumn{7}{|l|}{ Child characteristics } \\
\hline Child's skin colour (white) $(n=3326)$ & 1165 & 67.4 & 1074 & 67.3 & 2239 & 67.3 \\
\hline Low birth weight $(<2500 \mathrm{~g})(\mathrm{n}=3532)$ & 128 & 7.0 & 149 & 8.8 & 277 & 7.8 \\
\hline Prematurity ( $<37$ weeks) ( $n=3529)$ & 228 & 12.4 & 221 & 13.1 & 449 & 12.7 \\
\hline \multicolumn{7}{|l|}{ Injuries between 24 and 48 months (yes) } \\
\hline Falls $(n=3532)$ & 1319 & 71.2 & 1145 & 67.6 & 2464 & 69.8 \\
\hline Cuts $(n=3531)$ & 590 & 32.1 & 485 & 28.6 & 1075 & 30.4 \\
\hline Burns $(n=3532)$ & 327 & 17.8 & 266 & 15.7 & 593 & 16.8 \\
\hline
\end{tabular}

weight', for which the prevalence was higher among girls, all other characteristics were similar between the sexes.

\section{Maternal depression}

During pregnancy, $24.3 \%$ of the mothers reported having either treated or untreated depression. At 12 and 24 months after childbirth, $14.8 \%$ and $15.8 \%$ of the mothers presented EPDS $\geq 13$ (table 1). Among the boys, $23.0 \%$ of the mothers had been depressed 1-2 times and $14.8 \%$ were always depressed, whereas $62.9 \%$ had never being depressed. Among the girls, $25.1 \%$ of the mothers had been depressed 1-2 times and $13.6 \%$ were always depressed, whereas $61.3 \%$ had never being depressed (data not shown).

\section{Injuries between $\mathbf{2 4}$ and $\mathbf{4 8}$ months}

The proportion of children who suffered at least one injury was $77.8 \%$, and this proportion was higher among boys $(79.4 \%$;
$95 \%$ CI 77.5 to 81.2$)$ than among girls $(75.9 \%$; $95 \%$ CI 73.9 to 77.9). The proportion of boys and girls who suffered falls was $71.2 \%$ and $67.6 \%$; cuts $31.1 \%$ and $28.6 \%$; and burns $17.8 \%$ and $15.7 \%$, respectively (table 1 ). The median number of injuries among boys was higher among those from mothers who always presented symptoms of depression $($ median $=4$ ) (data not shown). For girls, the medians were similar among the daughters of mothers who had 1-2 episodes of depression and among those who were always depressed (median $=3.5$ for EPDS $\geq 13$ ) (data not shown).

Table 2 shows the incidence rates of injuries according to episodes of maternal depression. Among the boys, the incidence of injuries was higher when mothers presented depressive symptoms at the three times evaluated (table 2). Among the girls, the incidence was higher when their mothers presented symptoms on at least one of the occasions evaluated (table 2). 
Table 2 Incidence of injuries and their respective $\mathrm{Cls}(95 \% \mathrm{Cl})$ according to episodes of maternal depression* $(n=3533)$

\begin{tabular}{llll}
\hline \multirow{2}{*}{ Maternal depression } & \multicolumn{3}{l}{ Incidence of injuries $(95 \% \mathrm{Cl})$} \\
\cline { 2 - 4 } & Boys & Girls & Total \\
\hline Never depressed & 7.79 & 6.22 & 7.05 \\
\hline \multirow{2}{*}{ Depressed 1-2 times } & $(7.62$ to 7.95$)$ & $(6.07$ to 6.37$)$ & $(6.94-7.16)$ \\
& 7.96 & 8.26 & 8.11 \\
Always depressed & $(7.69$ to 8.23$)$ & $(8.0$ to 8.4$)$ & $(7.92-8.31)$ \\
& 9.45 & 8.36 & 8.94 \\
\hline
\end{tabular}

*Edinburgh Postnatal Depression Scale $\geq 13$.

Table 3 presents the crude and adjusted IRRs for injuries, according to maternal depressive symptoms. Both sexes presented higher incidence as the exposure to maternal depression increased, and girls presented higher risk than boys. In the adjusted analysis, the boys whose mothers were always depressed, the incidence of injuries was $18 \%(1.18 ; 95 \%$ CI 1.03 to 1.36$)$ higher than what was observed among those whose mothers had never been depressed.

Among the girls, in the adjusted analysis, the IRR values were quite similar between those whose mothers were depressed on $1-2$ occasions or on all three occasions. The daughters whose mothers suffered 1-2 depressive episodes presented incidence that was $31 \%$ higher $(1.31 ; 95 \%$ CI 1.15 to 1.50$)$, and among those whose mothers were always depressed, the incidence was $34 \%$ higher $(1.34 ; 95 \%$ CI 1.13 to 1.58$)$ than among the daughters whose mothers were never depressed (table 3).

Analyses of association between maternal depression and each of the injuries separately showed that for falls the IRRs were similar to those observed for the composite variable (with the three types of injuries taken together) (online supplemental tables $2 \mathrm{~A}$ and $3 \mathrm{~A}$ ). The incidence of cuts and burns showed the same direction of increased risk with increased exposure to maternal depression but with CIs including the value 1 (online supplemental tables $2 \mathrm{~B}, 2 \mathrm{C}, 3 \mathrm{~B}$ and $3 \mathrm{C}$ ).

\section{DISCUSSION}

The results from the present study showed that maternal depression is associated with higher incidence of injuries among children of both sexes aged 2-4 years, even after adjustment for confounding factors. The risk was higher among girls.

This study is among the few that have investigated the association between maternal depression and injuries during childhood.
A search in PubMed, Web of Science and PsycINFO databases, without publication year or language restrictions, found only four studies that specifically evaluated such association. ${ }^{8-10} 19$

A cohort study conducted in the USA with children under 6 years of age examined the relationship between depressive symptoms in mothers and injuries in children. The outcome included all lesions attended by a health professional, and the depressive symptoms of the mother were assessed by means of the Center for Epidemiologic Studies Depression Scale. ${ }^{20}$ In boys, the risk of reported injury increased by $4 \%$ for each one-point increase in maternal depressive symptoms. Among the girls, no association was found. ${ }^{19}$

A study conducted in Japan, in 2012, investigated the association between postpartum maternal depression and unintentional injuries among children aged 3-4 months. Children whose mothers had a EPDS score $\geq 9$ were more likely to suffer some kind of injury than were children whose mothers were not depressed (OR 1.59; 95\% CI 1.24 to 2.04). ${ }^{8}$

In the UK, in 2012, a case-control study using Nationwide Primary Healthcare Services database to investigate risk factors for the occurrence of the first medically recorded injury among children under 5 years of age found that $17 \%$ of burns were attributed to maternal depression (defined as clinical diagnosis of depression during pregnancy or in the first six months after delivery). ${ }^{9}$ Maternal depression was also found to be a risk factor for occurrences of poisoning, which comprised 33\% of the injuries. ${ }^{9}$

A study conducted in England, in 2017, with data from the health services, investigated the relationship between duration of maternal depression or anxiety episodes and rates of poisoning, fractures, burns and serious injuries among children up to 5 years of age. Poisoning and burn rates increased as the duration of maternal depression and anxiety episodes increased. ${ }^{10}$

Depression is a common mental disorder that affects approximately 350 million people of all ages throughout the world, and women are most affected. ${ }^{21}$ Studies conducted on postpartum women show that the prevalence of depression may be as high as $40 \% .{ }^{22}$ The arrival of a new baby generates physical, hormonal, mental and social changes that can place women in a vulnerable situation, which may directly reflect in their mental health and in the development of postpartum depression. ${ }^{23}$ Maternal depression is related to higher risks of behavioural problems among children, such as aggressiveness, impulsivity and hyperactivity. ${ }^{24} 25$ Children with behavioural problems are at a higher risk of injuries, as observed by Martins, in a systematic review of risk factors for injuries during childhood. ${ }^{5}$ Additionally,

Table 3 IRRs of injuries among children aged 24-48 months, according to exposure to maternal depression during pregnancy and at 12 and 24 months post partum (EPDS $\geq 13)$ : 2004 Pelotas Birth Cohort, $R S$, Brazil $(n=3289)$

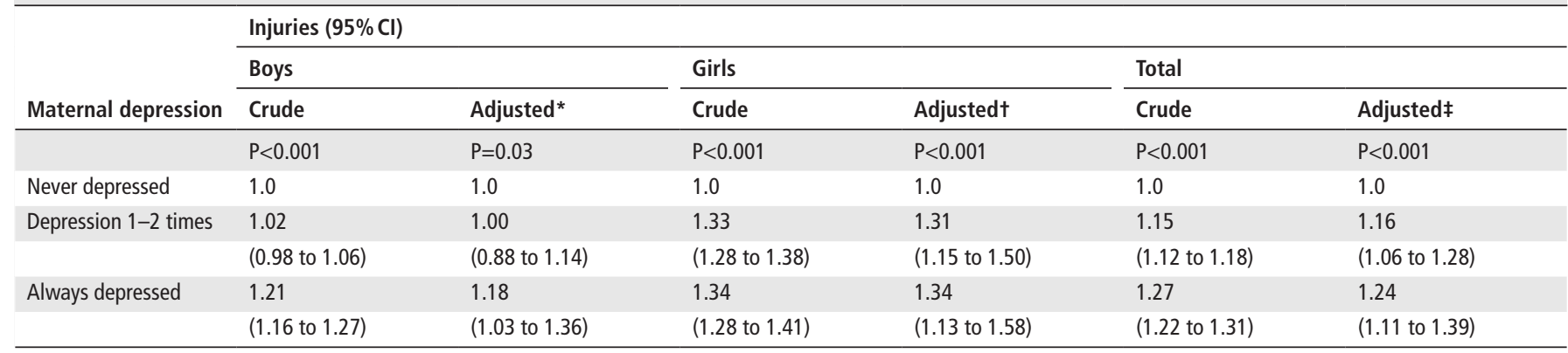

Model adjusted for

*Brazilian National Economic Index, mother's age, live with a partner and maternal smoking.

†Brazilian National Economic Index, mother's education level, mother's age, planned pregnancy, type of family.

$\ddagger$ Brazilian National Economic Index, mother's education level, mother's age, maternal smoking, planned pregnancy, child’s skin colour and birth weight. 
characteristics of depressive disorder itself like lethargy ${ }^{26}$ might cause mothers to pay less attention to security advice and child supervision, as well as to be less promptly responsive to unsafe situations.

In this study, the association between maternal depression and child injuries was more consistent among girls whose IRR values increased as the frequency of maternal depression symptoms increased. It is unclear whether girls would be more sensitive to maternal depression than boys or mothers of girls would report more easily the occurrence of any injury. There are reports that mothers protect girls more than they protect boys. ${ }^{18} \mathrm{~A}$ study conducted by Phelan et $a l^{27}$ investigated maternal reports regarding the time spent taking care of their children during their first three years of life. A longer time was spent supervising girls than was spent on boys, and this supervision was considered by the mothers to be 'intense' ${ }^{27}$ In addition, studies conducted on animals showed that females had higher vulnerability to intrauterine stress. ${ }^{28}$ Other studies on animals indicated that female fetuses were more susceptible to anxiety, stress and depression during their adult stage if exposed to these factors during the prenatal period. ${ }^{29}$ Nonetheless, the only other study that conducted stratified analyses according to the child's sex found a greater risk of injuries among boys than among girls of depressed mothers. ${ }^{19}$

Strengths and limitations of the current study should be recognised. Among the positive characteristics, the fact that it is a population-based study ensures the representativeness of the sample, allowing the results to be extrapolated to the same-age population in Pelotas and in settings with similar sociodemographic characteristics. The great majority of studies on childhood injuries were performed using samples from hospitals, emergency rooms and medical offices. Another positive aspect of the study was the low loss rate in all follow-ups, which may have helped to minimise selection bias. The follow-up period was also a positive factor because this study used data from the child's birth and all reports of maternal depression were included from the time of pregnancy until the child reaches 24 months of age. Among the limitations, there was no information on the behaviour of the children until they were 4 years of age. Therefore, children's behaviour could not be tested as a mediator variable between maternal depression and injuries. Nor were the situations that led to the injury investigated, which might have identified the person who was taking care of when the injury took place, and where it happened. In addition, no measure of severity was used to filter the injuries and no questions were asked regarding whether any medical care or first aid was required, thus eliciting that very minor lesions were recorded as an injury. However, the retrospective maternal recall to report on injuries in children over the previous twoyears would favour the report of more severe injuries. Also, two different approaches were used to build the composite variable maternal depression (self-reported maternal information from pregnancy and application of EPDS at 12-month and 24-month follow-ups). However, a previous analysis of the cohort showed a strong association between reported maternal depression in pregnancy and trajectories of depression (as assessed by EPDS) from 3 months to 6 years after the delivery. ${ }^{25}$ Also, because the information given was depended on the mother's or caretaker's perception of occurrences of injuries, it is possible that the injury rates among depressed mothers have been underestimated or overestimated. ${ }^{30}$

\section{CONCLUSION}

Depression is a frequent health problem among women in reproductive ages, and the negative effect of maternal depression over the child health has been extensively reported in the literature. ${ }^{26}$ The current study adds consistency to the findings from recent researches ${ }^{7-10}$ showing that depressive symptoms in mothers are associated with the risk of injury among children and raises a new hypothesis that maternal depression may be especially risky for girls. Further studies specifically planned to address this objective as well as to explore the potential mechanism through which maternal depression leads to increased risk of injuries are needed. Recognition and management of maternal depression may help to promote maternal well-being and reduce child injuries.

\section{What is already known on the subject}

The association between maternal depression and child injuries has scarcely been investigated. Only four studies were found in the literature, which showed that postpartum maternal depression was associated with unintentional injury among children under 5 years of age.

\section{What this study adds}

In this population-based birth cohort, maternal depression during pregnancy and at 12 and 24 months post partum was associated with increased incidence of unintentional injuries among children aged $2-4$ years, especially among girls.

Contributors RSB and ISS conceived the work, conducted the analyses and drafted the first version of the manuscript. AM, LA and FCB revised the manuscript critically and contributed with interpretations of the findings. All authors approved the submitted version of the manuscript.

Funding Wellcome Trust (086974/Z/08/Z), World Health Organization (03014HNI), National Support Program for Centers of Excellence (PRONEX) (04/0882.7), the Brazilian National Research Council (CNPq) (481012-2009-5), Brazilian Ministry Health (4589-04), and Children's Pastorate.

\section{Competing interests None declared.}

Ethics approval The present study, in all its phases, was approved by the Research Ethics Committee of the Medical School of the Federal University of Pelotas, which is affiliated to the Brazilian National Commission for Research Ethics (CONEP).

Provenance and peer review Not commissioned; externally peer reviewed.

Open access This is an open access article distributed in accordance with the terms of the Creative Commons Attribution (CC BY 4.0) license, which permits others to distribute, remix, adapt and build upon this work, for commercial use, provided the original work is properly cited. See: http://creativecommons.org/licenses/by/4.0/

Author note This article is based on data from the study "Pelotas Birth Cohort, 2004" conducted by Postgraduate Program in Epidemiology at Universidade Federal de Pelotas, with the collaboration of the Brazilian Public Health Association (ABRASCO). From 2009 to 2013, the Wellcome Trust supported the 2004 birth cohort study.

(C) Article author(s) (or their employer(s) unless otherwise stated in the text of the article) 2019. All rights reserved. No commercial use is permitted unless otherwise expressly granted.

\section{REFERENCES}

1 Hyder AA, Sugerman D, Ameratunga S, et al. Falls among children in the developing world: a gap in child health burden estimations? Acta Paediatr 2007:96:1394-8.

2 World Health Organization. Child injuries in context. World report on child injury prevention. Geneva: World Health Organization, 2008

3 Barcelos R, Santos IS, Matijasevich A, et al. Injuries from accidents between 0-4 years of age among children from the 2004 Pelotas Birth Cohort. Cad Saude Publica 2017;33:e00139115.

4 Baracat ECE, Paraschin K, Nogueira RJN, et al. Accidents involving children in the region of Campinas, Brazil. J Pediatr 2000;76:368-74.

5 Martins CB. [Accidents and violence in childhood and adolescence: risk and protective factors]. Rev Bras Enferm 2013;66:578-84. 
6 Schwebel DC, Brezausek CM. Chronic maternal depression and children's injury risk. $J$ Pediatr Psychol 2008:33:1108-16.

7 Brown G, Davidson S. Social class, psychiatric disorder of mother, and accidents to children. The Lancet 1978:311:378-81.

8 Yamaoka Y, Fujiwara T, Tamiya N. Association between maternal postpartum depression and unintentional injury among 4-month-old infants in Japan. Matern Child Health J 2016;20:326-36.

9 Orton E, Kendrick D, West J, et al. Independent risk factors for injury in pre-school children: three population-based nested case-control studies using routine primary care data. PLoS One 2012;7:e35193.

10 Baker R, Kendrick D, Tata LJ, et al. Association between maternal depression and anxiety episodes and rates of childhood injuries: a cohort study from England. Inj Prev 2017:23:396-402.

11 Barros AJ, Santos IS, Matijasevich A, et al. Methods used in the 1982, 1993, and 2004 birth cohort studies from Pelotas, Rio Grande do Sul State, Brazil, and a description of the socioeconomic conditions of participants' families. Cad Saude Publica 2008:24(suppl 3):s371-80

12 Barros AJ, da Silva dos Santos I, Victora CG, et al. [The 2004 Pelotas birth cohort: methods and description]. Rev Saude Publica 2006:40:402-13.

13 Santos IS, Barros AJ, Matijasevich A, et al. Cohort profile: the 2004 Pelotas (Brazil) birth cohort study. Int J Epidemiol 2011;40:1461-8.

14 Santos IS, Barros AJ, Matijasevich A, et al. Cohort profile update: 2004 Pelotas (Brazil) Birth Cohort Study. Body composition, mental health and genetic assessment at the 6 years follow-up. Int J Epidemiol 2014:43:1437a-f.

15 Cox JL, Holden JM, Sagovsky R. Detection of postnatal depression. Development of the 10-item edinburgh postnatal depression scale. Br J Psychiatry 1987:150:782-6.

16 Santos IS, Matijasevich A, Tavares BF, et al. Validation of the Edinburgh Postnatal Depression Scale (EPDS) in a sample of mothers from the 2004 Pelotas Birth Cohort Study. Cad Saude Publica 2007;23:2577-88.

17 Barros AJ, Victora CG. [A nationwide wealth score based on the 2000 Brazilian demographic census]. Rev Saude Publica 2005;39:523-9.
18 Balan B, Lingam L. Unintentional injuries among children in resource poor settings: where do the fingers point? Arch Dis Child 2012:97:35-8.

19 Phelan K, Khoury J, Atherton H, et al. Maternal depression, child behavior, and injury. Inj Prev 2007;13:403-8.

20 Weissman MM, Sholomskas D, Pottenger M, et al. Assessing depressive symptoms in five psychiatric populations: a validation study. Am J Epidemiol 1977;106:203-14.

21 World Health Organization. Depression. 2016 http://www.who.int/mediacentre/ factsheets/fs369/en/index.html (accessed 9 Feb 2016).

22 Ruschi GEC, Sun SY, Mattar R, et al. Aspectos epidemiológicos da depressão pósparto em amostra brasileira. Rev Psiquiatr RS 2007;29:274-80.

23 Camacho RS, Cantinelli FS, Ribeiro CS, et al. Psychiatry disorders in pregnancy and puerperium: classification, diagnosis and treatment. Rev Psiq Clin 2006;33:92-102.

24 Barker ED, Copeland W, Maughan B, et al. Relative impact of maternal depression and associated risk factors on offspring psychopathology. Br J Psychiatry 2012;200:124-9.

25 Matijasevich A, Murray J, Cooper PJ, et al. Trajectories of maternal depression and offspring psychopathology at 6 years: 2004 Pelotas cohort study. J Affect Disord 2015:174:424-31.

26 Agnafors S, Sydsjö G, Dekeyser L, et al. Symptoms of depression postpartum and 12 years later-associations to child mental health at 12 years of age. Matern Child Health J 2013:17:405-14.

27 Phelan KJ, Morrongiello BA, Khoury JC, et al. Maternal supervision of children during their first 3 years of life: the influence of maternal depression and child gender. J Pediatr Psychol 2014;39:349-57.

28 Richardson $\mathrm{HN}$, Zorrilla EP, Mandyam CD, et al. Exposure to repetitive versus varied stress during prenatal development generates two distinct anxiogenic and neuroendocrine profiles in adulthood. Endocrinology 2006;147:2506-17.

29 Glover V, Hill J. Sex differences in the programming effects of prenatal stress on psychopathology and stress responses: an evolutionary perspective. Physiol Behav 2012;106:736-40

30 Carlesso JPP, Souza APRde. Dialogia mãe-filho em contextos de depressão materna: revisão de literatura. Revista CEFAC 2011;13:1119-26. 